\title{
The Economics of IPR Protection Policies: Reply
}

\author{
RICARD GIL * \\ Department of Economics, UC Santa Cruz
}

\begin{abstract}
In a comment to my paper “The Economics of IPR Protection Policies,” Martínez-Sánchez (2007) shows that in my model under certain conditions the presence of piracy increases the quantity produced by the legal monopolist firm. In this note, I show how the algebra used in MartínezSánchez (2007) may be misleading and clarify under what assumptions such a finding would emerge. Finally, I discuss the validity of the assumptions in my model that would yield such counterintuitive finding.
\end{abstract}

\section{Introduction}

The growing importance of piracy is a major concern for governments and media industries managers around the world. Governments from developing countries blame piracy and IPR violators for scaring away foreign investment and slowing economic growth. Similarly, media industry practitioners blame piracy and IPR violators for the recent decrease in global music and movie sales due to the proliferation of pirate DVD sales and internet downloads (see IFPI reports, Gil, 2006 or Zentner, 2006 for an accurate description).

To study the problem of how governments should combine demand-side and supplyside policies, I use an extension of Shaked and Sutton (1982) that models the competition between a monopolist legal producer and a competitive fringe of illegal producers. This model allows for endogenous prices for legal and pirate products as well as endogenous entry of illegal producers. The entry of legal producers is necessarily taken as given since the illegal producers would have no product to copy if there had not been a legal product in the market in the first place.

The paper shows that under some scenarios, the model may predict that legal quantity produced in the market may be higher in the presence of piracy but this result hinges on what goal the government is pursuing when setting taxes on the pirated product and whether the participation constraint of the illegal producer is satisfied. Finally, the paper discusses how realistic are some of the assumptions that makes this result go through, therefore how seriously policy makers and practitioners should take such finding.

* Contact Author. Mailing address: University of California, Santa Cruz Economics Department, 401 E2 Building, University of California, Santa Cruz, CA 95064. Office Phone number: (831) 459-4924. Email: rgil@ucsc.edu 


\section{$2 \quad$ Working within the model}

In his note, Martínez-Sánchez (2007) shows that the demand of the monopolist legal producer will be larger in the presence of piracy than in the absence of it if it is true that

$$
\frac{\theta_{2}}{\theta_{1}}>\frac{c_{2}+t_{2}}{\frac{c_{1}}{1-h(G)}} .
$$

If marginal costs of production are set equal to each other and taxes are close to zero, this condition will always hold. The expression above is not quite right because it assumes that the tax the government will choose under both scenarios is the same. If no piracy exists, the government will choose the level of taxation $t_{2}{ }^{n p}$ optimally to minimize the sum of the deadweight loss created by taxes across all goods. If piracy exists, the legal monopolist will face a different demand curve and the government will impose a different tax level $t_{2}^{p}$ depending on the goal of the government and the different levels of spending (in the model if there is no piracy $G$ should equal 0 , but the government still needs to pay $\mathrm{R})$. Taking into account this, the expression above converts into

$$
\frac{\theta_{2}}{\theta_{1}}>\frac{c_{2}+t_{2}^{n p}}{\frac{c_{1}}{1-h(G)}-t_{2}^{p}+t_{2}^{n p}} .
$$

This expression is similar to the one above but it recognizes the fact that the level of taxation $t_{2}$ and spending $\mathrm{G}$ will depend on the goal of the government as explained in Gil (2006). It could be the case that taxes in the presence of piracy are slightly higher than in the absence of it. In such case, even if marginal costs are very similar or taxes in the absence of piracy are close to zero, the above expression may not hold. Yet, if piracy does not exist, it would be optimal for the government to set a positive tax given the demand elasticity of the good.

Since imposing lower taxes and assuming marginal costs of legal products as low as marginal costs of illegal products will lower the total price paid by consumer for the legal product, the revenues of the illegal sector will go down. Therefore, we need to consider explicitly the participation constraint of the illegal producers. According to the paper, this participation constraint establishes that

$$
\Pi_{1}=d_{1}\left(p_{1}\right)\left(p_{1}[1-h(G)]-c_{1}\right) \geq 0 \text {. }
$$

Given this condition and the result that $p_{1}=\frac{c_{1}}{1-h(G)}$ under perfect competition, $\Pi_{1} \geq 0$ will hold as long as $d_{1}\left(p_{1}\right) \geq 0$. For this condition to be true, it must be that the legal producers face some residual demand in the distribution of consumers specified in the model. Given this characterization, the illegal producers will face positive demand as long as the indifferent consumer between buying legal and pirate products $\left(s^{*}=\frac{p_{2}-p_{1}}{\theta_{2}-\theta_{1}}\right)$ does 
not locate to the left of the indifferent consumer between buying pirate and none $\left(s^{\prime}=\frac{p_{1}}{\theta_{1}}\right.$ ). In other words, it must be true that

$$
\frac{p_{2}-p_{1}}{\theta_{2}-\theta_{1}}>\frac{p_{1}}{\theta_{1}}
$$

Since we know the optimal pricing of $p_{2}$ and $p_{1}$, we plug those expressions in and find that this will hold if

$$
\frac{\frac{k \Delta \theta+c_{2}-t_{2}^{p}}{2}-\frac{c_{1}}{2(1-h(G))}}{\theta_{2}-\theta_{1}} \geq \frac{\frac{c_{1}}{1-h(G)}}{\theta_{1}} .
$$

This expression may not hold in scenarios where the difference $\theta_{2}-\theta_{1}$ is large, $\theta_{1}$ low enough and high enough level of spending $G$, regardless of the values taken by other parameters. In the case of equal marginal costs and a tax close to zero, it is always true that illegal producers face positive demand and would participate in this market.

\section{$3 \quad$ Realism of model and assumptions in the real world}

My model offers the prediction that if marginal costs of legitimate and illegitimate producers were equal and the government would not tax these goods with or without the presence of piracy we should observe an increase of sales in the presence of piracy. This section draws a parallelism between the mechanisms in my model and the real world, and tries to reconcile theory with the evidence that piracy has decreased sales of certain goods.

The model differs from the real world in how prices are set. In my model, producers are integrated with stores and set prices faced by consumers. In the real world, pricing of music is done at stores under vertical contracts with music producers and music distributors. These vertical contracts induce retailers to keep prices high and create certain degree of price stickiness (due to differences in incentives of the different agents involved) that prevents prices to adjust (decrease) in the short term when piracy increases. Since they will not adjust prices down, the quantity demanded (and supplied) will go down when piracy increases. In the long run, if the prices adjust and piracy prevails, we should observe the result in the comment of Martínez-Sánchez (2007). He compares quantities in equilibrium that are the result of combining shifts in the demand curve (inward when piracy increases) and movements along the curve (when prices go down). Therefore, we may observe under some parameters that piracy increases quantity supplied of the legal product in the market if the increase in quantity supplied due to the decrease in price more than compensates the decrease in quantity due to the shift inward of the residual demand curve faced by the legal producer. In the long run, we may expect piracy to disappear and tax levels to go down due to the policies undertaken by governments and agencies. If this is so, stores may not adjust prices and we may not observe the increase in sales that Martínez-Sánchez (2007) predicts.

The second remark complements the first in that I address how realistic is a scenario where taxes are set close to zero and marginal costs of both goods are equal to each other. 
In my model, I assume that legal producers pay a fixed cost and a marginal cost per unit produced, and the illegal producer only has marginal costs. Initially, I assume that the marginal cost of the legal producer is larger than the marginal cost of the illegal producer. This difference is justified by the imposed difference in quality (the illegal product is of lower quality). These assumptions may not be the best characterization of the cost structure existing in the real world. The model could be complicated further by requiring illegal producers to incur a fixed cost (lower than the fixed cost of legal producers) or even setting higher marginal costs than the legal producers. This could explain why illegal producers tend to be smaller than that of legal producers, aside from the willingness to escape detection and arrest by the authorities. In any case, the introduction of a fixed cost or even higher marginal costs of production of illegal products (equal to marginal costs of legal products) will definitely tighten the participation constraint of illegal producers and drive them out of business in the scenario presented by Martínez-Sánchez (2007).

Finally, it is true that governments are lowering taxes on pirated goods as a way to fight piracy and this is increasing the quantity demanded of legal products. This is consistent with Gil (2006) but the assumption that government taxes will ever be zero or close to zero is far from being true under both scenarios considered (piracy and no piracy). We still do not know what demand would be like in a world with no piracy. Assuming therefore that taxes under both scenarios will be equal to each other and to zero is unrealistic.

\section{Conclusions}

The results provided here show that under some conditions in Gil (2006), legal producers may produce (and sell) more units in the presence of piracy than in the absence of it. I show that this result not only depends on the cost structure of the firms involved but also on the goals of the government when choosing levels of taxation and spending.

Despite this, I argue that the conditions under which these results arise are unlikely to take place in the industries threatened by piracy. Therefore, policy makers and government officials that shape piracy policy should disregard the misleading policy implication that allowing a competitive fringe of illegal producers may increase the quantity supplied by legal producers.

\section{$5 \quad$ References}

Gil, R. (2006) "The Economics of IPR Protection Policies," Review of Network Economics, 5: 299-319.

Martínez-Sánchez, F. (2007) “The Economics of IPR Protection Policies: Comment," Review of Network Economics, 6: 525-529

Shaked, A. and J. Sutton (1982) "Relaxing Price Competition through Product Differentiation,” Review of Economic Studies, 49: 3-13. 
Zentner, A. (2006) "Measuring the Effect of Online Music Piracy on Music Sales," Journal of Law and Economics, 49: 63-90. 